\title{
PENGUKURAN KEPEMIMPINAN PEMBELAJARAN KEPALA SEKOLAH DALAM MEMBANGUN KARAKTER SISWA
}

\author{
Basri \\ SMP Negeri 4 Gresik \\ bisri@yahoo.co.id
}

\begin{abstract}
Abstrac
Learning leadershipthat combines self awareness, self regularly, and value based leadership becomes an answer to find out the figure of leader who is able to implement value system to their followers. The purposes of research are to examine how important is virtues of learning ladership and to examine multidimensionality of learning leaderhip. Result shows that learning leadership isa suitable type of leadership to implement the value system effectively for grow of sudents character. Result also shows that learning leadership is a unidimensional construct.
\end{abstract}

Keywords: measuring, learning leadership, students character

\begin{abstract}
Abstrak
Salah satu alasan masyarakat meragukan keberadaan pemimpin yang dapat menumbuhkan karakter siswa adalah masih terjadinya tawuran di kalangan pelajar. Kepemimpinan pembelajaran menjadi jawaban ditemukannya pigur pemimpin yang dapat menumbuhkan karakter pada para pengikutnya.Penelitian ini bertujuan untuk menguji tingkat penting perilaku menunjukkan moral tinggi dalam kepemimpinan pembelajaran dengan metode Delphi Survey dan menguji multidimensionalitas kepemimpinan pembelajaran. Hasil penelitian menunjukkan bahwa kepemimpinan pembelajaran adalah tipe kepemimpinan yang tepat untuk menumbuhkan karakter siswa secara efektif.Hasil penelitian juga membuktikan bahwa kepemimpinan pembelajaran merupakan konstruksi yang bersifat unidimensional.
\end{abstract}

Kata kunci: pengukuran, kepemimpinan pembelajaran,karakter siswa

\section{PENDAHULUAN}

Salah satu isu penting dalam penyelenggaraan pendidikan di Indonesia sekarang ini adalah peningkatan mutu pendidikan. Sinyalemen yang ada, telah terjadi penurunan mutu pendidikan pada semua jenjang. Hal ini berlangsung akibat penyelenggaraan pendidikan yang lebih menekankan pada aspek kuantitas dan kurang diikuti dengan aspek kualitas (Agung, 1992; Idris,
2005). Di samping itu, faktor mutu sangat ditentukan oleh kepemimpinan kepala sekolah, terutama kepemimpinan pembelajaran.

Kepemimpinan pembelajaran sangat cocok diterapkan di sekolah karena misi sekolah adalah mendidik semua siswa dan memberikan kesempatan kepada mereka untuk memperoleh pengetahuan, keterampilan, dan nilai-nilai (Fink \& Lauren, 2003). Siswa menjadi 
dewasa yang sukses dan berkarakter dalam menghadapi masa depan yang belum diketahui dan sarat dengan tantangan yang sangat turbulen. Misi inilah menuntut sekolah sebagai organisasi harus memfokuskan pada pembelajaran yang meliputi kurikulum, proses belajar dan pembelajaran, dan evaluasi hasil belajar.

Kepemimpinan pembelajaran, sampai saat ini dipercaya sebagai faktor penting yang mempengaruhi perilaku orang, menjadikan organisasi menjadi sangat terkenal, berkembang dan maju. tetapi tidak sedikit pula beberapa organisasi yang sudah sangat maju, lambat laun menjadi redup bahkan terpuruk. Avolio\& Gardner (2005) menyatakan bahwa ia tidak pernah melihat sekolah yang bagus dipimpin oleh kepala sekolah yang buruk dan sekolah buruk dipimpin oleh kepala sekolah yang baik. Dia juga menemukan sekolah yang gagal dan berubah menjadi sukses, sebaliknya sekolah yang sukses tiba-tiba menurun kualitasnya.Ryan (2008) mengatakan bahwa naik atau turunnya kualitas sekolah sangat bergantung pada kualitas kepala sekolahnya.

Kepemimpinan melalui prosesnya yang panjang mampu menyulap gairah orang-orang yang ada di dalamnya, atau sebaliknya menjadi sangat tertekan dan gelisah.Supardi (2011) menekankan bahwa akibat krisis kepemimpinan, banyak orang yang menderita, yang mengalami burn-out, yang tidak dapat menikmati hidup dalam pekerjaannya, serta banyak biaya yang dikeluarkan untuk mengobati sakit emosional di tempat kerja. Pentingnya arti kepemimpinan bagi organisasi menjadi kebutuhan yang sangat mendesak untuk diberikan pendidikan kepemimpinan bagi para manajer pembelajaran di sekolah.

Beberapa teori kepemimpinan dalam perkembangannya telah menekankan bahwa fokus kepemimpinan harus digeser dari orientasi perilaku ke orientasi tugas dan hasil pekerjaan pembelajaran. Hal ini didasari suatu praktlk kepemimpinan yang gagal menciptakan efektivitasnya karena terlalu berbelas kasihan, kurang tegas dan tidak disiplin. Namun rupanya penerapan teori yang berorientasi tugaspun acapkali menimbulkan masalah kemanusiaan dan menyeret orang-orang yang terlibat di dalamnya kurang memperhatikan sifat dan perilaku baik untuk pengangkatan pemimpin maupun dalam proses kepemimpinan.

Penerapan teori kepemimpinan yang dilakukan kepala sekolah didasarkan pertimbangan misi luhur sekolah yang berbeda karakteristiknya dengan organisasi lain. Sekolah dengan misi utama menumbuhkan karakter dan mengajarkan moral sangat lekat dengan orientasi perilaku kepemimpinan yang didasarkan kesadaran diri, panggilan jiwa dan tanggungjawab intrinsik untuk memimpin dengan pembelajaran yang bermutu menjadi fokusnya mencakup tiga ranah, yaitu kognitik, keterampilan, dan afektif atau moralitas (karakter siswa sesuai dengan nilai-nilai Pancasila).

Moral feeling menempati ranah afektif meliputi enam aspek: (1) suara hati (conscience), (2) harga diri (selfesteem), (3) empati (empathy), (4) kasih sayang (loving the good), (5) pengendalian diri (self-control), dan (6) rendah hati (humility). Moral actions menempati ranah psikomotorik, berupa perilaku sebagai perwujudan dari moral knowing dan moral feeling.Perilaku moral 
seseorang didasari kompetensi, niat, dan kebiasaan yang sudah dimiliki (Zuchdi, 2012). Karena pentingnya penumbuhan karakter siswa tersebut, kepala sekolah harus melakukan manajemen pendidikan karakter (Mulyasa, 2011).

\section{METODE}

Perilaku

kepemimpinan pembelajaran yang digunakan dalam penelitian ini didasarkan lima aspek dariGeorge (2003) yaitu purpose, values, heart, relationships, dan selfdisciplineyang dipadukan dengan konsep Kernis (2003) yang mengidentifikasi empat elemen utama authenticity yaitu: self-awareness, unbiased processing, relational authenticity, dan authentic behavior/action dan hasil penelitian Avolio\& Gardner (2005) yang menggunakan The ALQ scales yaitu: self awareness, transparency, ethical/moral, danbalanced processing. Penelitian ini menggunakan enam aspek hasil analisis gabungan ketiganya, yaitu: self-awareness/heart,purpose, values/ethical/moral, relationships, self-discipline/authentic,

behavior/action, dantransparency. Perilaku kepemimpinan pembelajaran dalam penelitian ini mencakup enam aspek yang berisi 32 item dengan jumlah item untuk aspek self awareness tujuh, purpose/vision danbehavior enam, values dan transparancy lima item, dan relationship empat item. Opsi untuk tiap item digunakan lima skala: TP (Tidak Penting), KP (Kurang Penting), $P$ (Penting), SP (Sangat Penting), dan SPS (Sangat Penting Sekali atau Keharusan). Metode Delphi Survey digunakan untuk pengujian tingkat penting perilaku kepemimpinan pembelajaran dengan partisipannya adalah 22 pengawas mantan kepala
SMP di Kabupaten Gresik. Pangkat partisipan rata-rata berada pada pembina dengan usia dan masa kerja yang sangat variatif. Partisipan diminta untuk menilai tingkat penting dari 30 perilaku kepemimpinan pembelajaran agar sekolah dapat menumbuhkan karakter. Sampel pemimpin sekolah yang dipilih adalah kepala sekolah. Situasi yang menjadi konteks penelitian adalah kompleksitas tanggung jawab kepala sekolah sebagai pemimpin dan manajer yang dihadapkan pada situasi untuk mencapai tujuan akademik yaitu siswa dengan nilai yang tinggi dan lulus ke pendidikan selanjutnya dengan akhlak yang baik, sementara tuntutan manajerial cukup ketat untuk membuat seluruh aspek pendidikan tertata dengan efektif dan efisien.

Data tingkat pentingnya kepemimpinan pembelajaran setelah diperoleh dilakukan pengujian multidimensionalitas konstruk yang dilakukan pada partisipan yang berbeda. Ketigapuluh item dipertahankan sebagai alat ukur kepemimpinan pembelajaran karena seluruh perilaku dinilai penting. Untuk menguji multidimensionalitas dilibatkan 62 orang kepala sekolah menengah pertama di Kabupaten Gresik yang diukur tingkat kepemimpinan pembelajaran. Kemudian data diolah dengan menggunakan koefisien reliabilitas Alpha Cronbach dan analisis faktor.

\section{HASIL DAN PEMBAHASAN}

Secara umum penelitian ini menghasilkan suatu temuan bahwa aspek perilaku merupakan yang paling utama karena seluruh aspek dinilai seluruhnya penting tidak ada yang tidak penting.Aspek visi, nilai, keterbukaan dan relasi memiliki item yang kurang penting, sedangkan aspek kesadaran diri terdapat item 
yang tidak penting, berikut rekapitalasi

Tabel 1.

hasil pengolahan data yang ditunjukan

Tabel 1.

Hasil Penilaian Partisipan Semua Aspek Kepemimpinan Pembelajaran

\begin{tabular}{lllllll}
\hline \multirow{2}{*}{ NO } & \multicolumn{1}{c}{ ASPEK } & \multicolumn{4}{c}{ KATEGORI $(\%)$} \\
\cline { 3 - 6 } & & TP & KP & P & SP & SPS \\
\hline 1 & Self awareness & 1,78 & 5,35 & 25 & 45,64 & 23,21 \\
2 & Purpose/Vision & & 4,16 & 18,75 & 27,5 & 35,42 \\
3 & Value/Etica/moral & & 2,5 & 27,5 & 27,5 & 42,5 \\
4 & Relationship & & 3,13 & 25 & 25 & 46,88 \\
5 & Behavior/self dicipline & & & 18,75 & 50 & 31,25 \\
6 & Transparancy & & 2,15 & 27,5 & 47,5 & 22,5 \\
\hline
\end{tabular}

Keenam aspek dalam kepemimpinan pemebelajarandinilai penting untuk dimiliki oleh pemimpin sekolah dalam menumbuhkan karakter siswa. Aspek Behavior/self dicipline dan relationship adalah yang dinilai paling tinggi nilai pentingnya oleh para partisipan, sedangkan aspek self awareness justru dinilai di bawah aspek lainnya oleh para partisipan. Bila diurutkan tingkat pentingnya tiap aspek dalam pandangan partisipan adalah, self dicipline/behavir, transparancy, value/etica/moral, relationship, purpose/vision, dan self awarenes.

Aspek perilakupartisipan tidak ada yang menilai tidak penting dan kurang penting, seluruhnya menilai penting sampai sangat penting sekali sebanyak $100 \%$. Aspek transparancy partisipan menilai penting sampai sangat penting sekali sebanyak $97,55 \%$, dan $2,45 \%$ kurang penting. Sedikit di bawahnya adalah aspekvalue/etica/moral yang dinilai partisipan $97,35 \%$ penting sampai sangat penting sekali, dan kurang penting 2,65\%. Aspek relationship memiliki nilai $96,45 \%$ penting sampai sangat penting sekali dan 3,55\% kurang penting. Aspek purpose/vision memiliki penilaian penting sampai sangat penting sekali sebanyak 95,75\% dan kurang penting 4,25\% sedangkan aspek behavior/self diciplineose dinilai sangat penting sampai penting sekali oleh 91,80\% partisipan, $8,20 \%$ menilai kurang penting sampai tidak penting.

$$
\text { Perilaku kepemimpinan }
$$

terpenting seorang pemimpin pembelajaran untuk dapat menumbuhkan karakter adalah behavior/self dicipline, bahwa nilai tertinggi seorang pemimpin dari apa yang dipikirkan dan disikapinya adalah terletak pada apa yang dilakukannya menjadi suri tauladan bagi para pengikutnya. Satunya kata dengan tindakan menjadi ukuran konsistensinya pemimpin dengan apa yang diucapkannya.

Tebel 2.

Self Regularly/Behavior

\begin{tabular}{llllllll}
\hline No & \multicolumn{1}{c}{ Pernyataan } & \multicolumn{4}{c}{ Tingkat Penting } \\
\hline 1 & Terjun dalam pelaksanaan program untuk & TP & KP & P & SP & SPS \\
& $\begin{array}{l}\text { menginspirasi orang lain } \\
2\end{array}$ & Memahami bahwa pelayanan adalah inti dari & TP & KP & P & SP & SPS
\end{tabular}



kepemimpinan pembelajaran
3 Banyak bekerjanya seimbang dengan apa yang dikatakannya
$4 \quad$ Memiliki kebiasaan bekerja keras dan pantang menyerah
$5 \quad$ Tidak mengeluh dan menyalahkan orang lain bila ditemukan kesalahan/kegagalan program
Sangat memprioritaskan kepentingan organisasi 6
Transparancy menduduki peringkat kedua sebagai aspek terpenting. Kepala Sekolah dituntut untuk memberdayakan semua orang untuk terlibat dalam program sekolah berdasarkan kapasitasnya dan memiliki anggapan bahwa semua

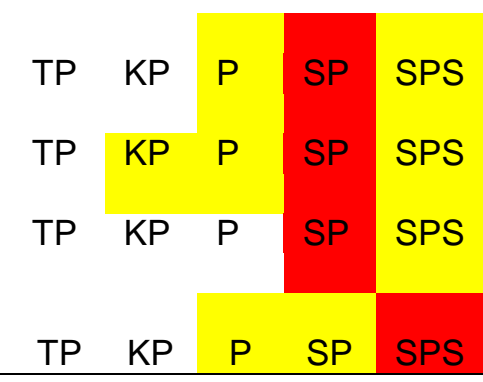

anggota sekolah berhak tahu tentang manajemen sekolah.Perilaku tersebut dinilai lebih penting daripada sekadar memampang laporan sekolah pada media.

Tebel 3.

Transparancy

\begin{tabular}{llllllll}
\hline No & \multicolumn{1}{c}{ Pernyataan } & \multicolumn{4}{c}{ Tingkat Penting } \\
\hline 1 & $\begin{array}{l}\text { Menerapkan managemen sekolah terbuka } \\
\text { Memberdayakan semua orang untuk terlibat dalam program } \\
\text { sekolah berdasarkan kapasitasnya }\end{array}$ & TP & KP & P & SP & SPS \\
3 & $\begin{array}{l}\text { Beranggapan bahwa semua onggota sekolah berhak tahu } \\
\text { tentang manajemen sekolah }\end{array}$ & TP & KP & P & SP & SPS \\
4 & $\begin{array}{l}\text { Laporan sekolah dipampang pada media yang mudah diakses } \\
\text { orang } \\
\text { Bersikap terbuka dan mudah diakses secara langsung maupun } \\
\text { melalui media komunikasi lainnya }\end{array}$ & TP & KP & P & SP & SPS \\
5 & KP & P & SP & SPS \\
\hline
\end{tabular}

Selanjutnya purpose/vision menjadi aspek terpenting ketiga. Kepala sekolah dituntut untuk membangun komitmen semua anggota organisasi untuk mewujudkan visi bersama, memiliki cita-cita menjadikan sekolah lebih maju, dan memiliki kesadaran akan suatu pandangan bahwa visi sendiri hanyalah mimpi. Visi bersama adalah kenyataan dan bersemangat untuk mengomunikasikan cita-cita memajukan sekolah kepada para anggota organisasi. Sebaliknya, membuat pertemuan untuk mempartisipasikan anggota organisasi dalam merumuskan visi bersama masih ada yang memandang kurang penting.

Tebel 4 .

\section{Purpose/Vision}

\begin{tabular}{llllll}
\hline No & Pernyataan & \multicolumn{3}{c}{ Tingkat Penting } \\
\hline 1 & $\begin{array}{l}\text { Saat pertama kali menjadi kepala sekolah tergambar } \\
\text { mimpi untuk menjadikan sekolah lebih maju ditangan- }\end{array}$ & TP & KP & SP & SPS \\
& nan & & &
\end{tabular}




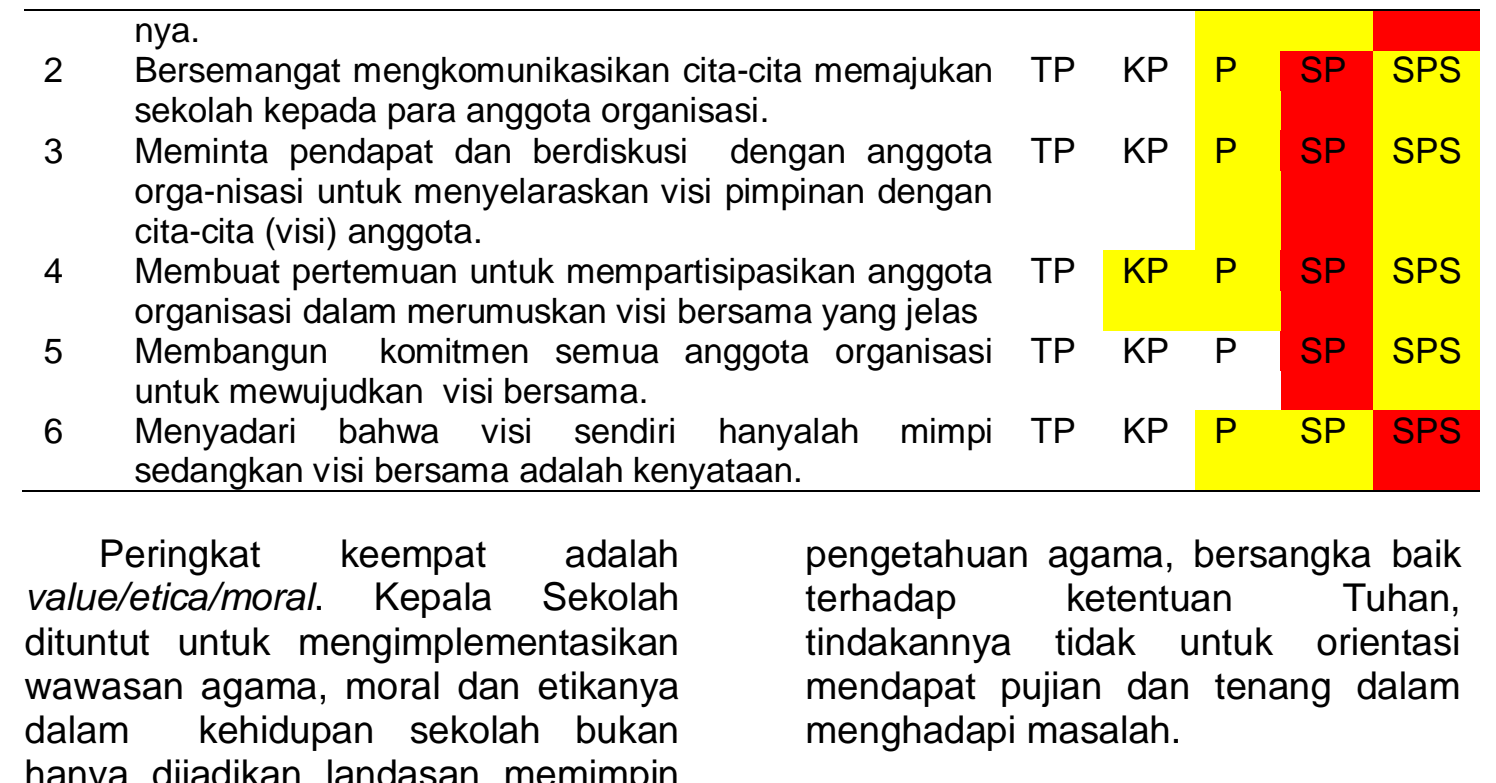

hanya dijadikan landasan memimpin

sekolah yang tertuang dalam

dokumen nilai-nilai sekolah, memiliki

Tabel 5.

Value

\begin{tabular}{lllllllll}
\hline No & \multicolumn{1}{c}{ Pernyataan } & \multicolumn{5}{c}{ Tingkat Penting } \\
\hline 1 & Tindakannya tidak untuk mendapat sanjungan/pujian. & TP & KP & P & SP & SPS \\
2 & $\begin{array}{l}\text { Memiliki pengetahuan agama yang cukup untuk pedo- } \\
\text { man kehidupannya. }\end{array}$ & KP & P & SP & SPS \\
3 & $\begin{array}{l}\text { Bersangka baik terhadap ketentuan Tuhan dengan } \\
\text { keya-kinan ada sesuatu yang akan diperoleh dari } \\
\text { kegagalan yang ditemui. }\end{array}$ & KP & P & SP & SPS \\
4 & $\begin{array}{l}\text { Tenang dalam menghadapi masalah dan } \\
\text { mengembalikan-nya kepada Tuhan. }\end{array}$ & KP & P & SP & SPS \\
Agama, moral dan etika bukan hanya dijadikan & TP & KP & P & SP & SPS \\
kehiduanan memimpin sekolah tapi direalisasikan dalam & & & & & \\
\hline
\end{tabular}

Peringkat kelima adalah interaksi edukatif.Kepala Sekolah dituntut untuk bersikap egaliter (dapat bergaul dengan siapapun) supel dan memiliki banyak teman, memiliki hubungan yang luas dengan berbagai kalangan yang dapat memperlancar usaha memimpin sekolah, menjalin kerjasama dengan pihak-pihak yang berkepen-tingan untuk kemajuan sekolah, dan pandai bernegosiasi untuk mendapatkan bantuan dan program dari pemerintah, orangtua maupun swasta.

Tabel 6.

Relationship

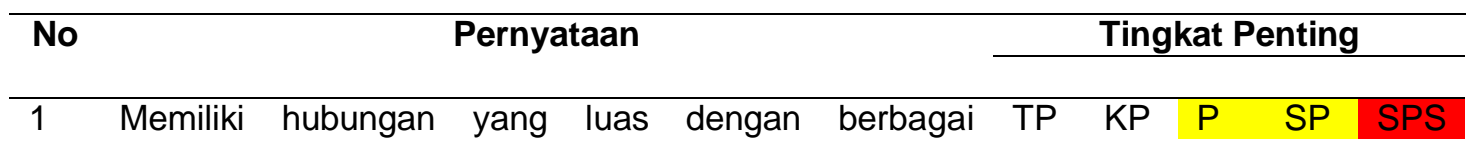




\begin{tabular}{lllllllll}
\hline kalangan yang dapat memperlancar usaha memimpin & & & & & \\
2 & $\begin{array}{l}\text { sekolah. } \\
\text { Menjalin kerjasama dengan pihak-pinak yang } \\
\text { berkepen-tingan untuk kemajuan sekolah }\end{array}$ & TP & KP & P & SP & SPS \\
3 & $\begin{array}{l}\text { Pandai bernegosiasi untuk mendapatkan bantuan dan } \\
\text { program dari pemerintah, orang tua maupun swasta. } \\
\text { Bersikap egaliter (dapat bergaul dengan siapapun) } \\
\text { supel dan memiliki banyak teman. }\end{array}$ & TP & KP & P & SP & SPS \\
\hline
\end{tabular}

Kesadaran diriyang diduga dapat dinilai sangat penting oleh banyak orang dalam konteks keaslian, justru berada pada peringkat terakhir dalam penelitian ini. Perilaku sangat penting sekali dalam aspek ini yang dituntut dilaksanakan kepala sekolah adalah kesiapan kepala sekolah menolong/membantu kesulitan bawahan, berbuat tulus tidak mengharap balas jasa, rendah hati dan tidak arogan. Sedangkan perilaku tidak mengungkit-ungkit jasanya sendiri, tidak tertarik pada sanjungan akan dirinya, dan keyakinan akan kesadaran diri dinilai masih ada yang menilai tidak penting untuk menjadi ukuran.

Tabel 7.

Self Awareness/Heart

\begin{tabular}{llllllll}
\hline No & \multicolumn{1}{c}{ Pernyataan } & \multicolumn{4}{c}{ Tingkat Penting } \\
\cline { 3 - 7 } & & & & & & \\
\hline 1 & Siap menolong/membantu kesulitan orang & KP & P & SP & SPS \\
2 & Tidak mengungkit-ungkit jasanya terhadap orang lain & TP & KP & P & SP & SPS \\
3 & Berbuat tulus tidak mengharap balas jasa & TP & KP & P & SP & SPS \\
4 & Tidak tertarik pada sanjungan untuk dirinya & TP & KP & P & SP & SPS \\
5 & Rendah hati dan tidak sombong & TP & KP & P & SP & SPS \\
6 & Tidak pamrih dalam membantu orang lain & TP & KP & P & SP & SPS \\
7 & $\begin{array}{l}\text { Menyakini bahwa kesadaran diri adalah yang utama } \\
\text { dalam memimpin }\end{array}$ & TP & KP & P & SP & SPS \\
\hline
\end{tabular}

Hasil penelitian ini bila dikomparasikan dalam hal urutan pentingnya tiap aspek dengan hasil penelitian yang dilakukan oleh George (2003) memang tidak sama, tetapi secara keseluruhan keberadaan tiap aspek tidak ada yang dinilai tidak penting. Pada penelitian George, untuk mendapatkan pemimpin yang otentik maka dimensi yang sangat penting dalam kepemimpinan adalah visi dan nilai sedangkan pada penelitian ini ada di disiplin diri dan transparansi yang disebut George dalam urutan keempat. Hasil penelitian George menunjukkan bahwa visi dan nilaiadalah prediktor terbaik dari hasrat pemimpin untuk melakukan kerja ekstra dan pelayanan kepemimpinan yang memberikan efek langsung terhadap semangat kerja pengikut karena adanya kejelasan apa yang harus dilakukan.Pemimpin yang memiliki disiplin diri adalah pemimpin yang terjun langsung dalam pelaksanaan program untuk menginspirasi orang lain, memahami bahwa pelayanan adalah inti dari kepemimpinan, banyak bekerjanya seimbang dengan apa yang dikatakannya, memiliki kebiasaan bekerja keras dan pantang menyerah, tidak mengeluh dan menyalahkan orang lain bila ditemukan 
kesalahan/kegagalan program, dan sangat memprioritaskan kepentingan organisasi.

Aspektransparansiyang tidak dijadikan dimensi kepemimpinan otentik oleh George (2003), justru menjadi dimensi terpenting yang kedua. Seorang pemimpin tetap diminta untuk menjadi model perilaku dengan menerapkan managemen sekolah secara terbuka, memberdayakan semua orang untuk terlibat dalam program sekolah berdasarkan kapasitasnya masingmasing, dan bersikap terbuka dan mudah diakses secara langsung maupun melalui media komunikasi lainnya. Munculnya dimensi transparansipada peringkat kedua memberikan justifikasi bahwa kepemimipnan

pembelajaranmerupakan bentuk kepemimpinan yang penting dalam mengelola sekolah karena transparansi bukan sekedar terbuka tetapi perlu keluasan hati untuk menerima kekurangan dan mengakui kelebihan orang dengan adanya pemberdayaan semua anggota organisasi.

Penciptaan, perumusan, implementasi dan evaluasi visi oleh seorang pemimpin dipandang strategis oleh teori maupun praktek sebagai hal yang paling penting.Namun dalam penelitian ini, visijustru menjadi dimensi terpenting yang ketiga. Pemimpin otentik adalah pemimpin dengan mimpi-mimpi menjadikan sekolah lebih maju ditangannya dan ini tidak hanya sebagai mimpi peribadi tetapi dishared sebagai milik bersama, sehingga ungkapan "mimpi sendiri adalah benar-benar mimpi, sedangkan mimpi bersama adalah kenyataan", tertanam dalam dirinya. Pemimpin otentik adalah pemimpin dengan tujuan yang jelas bukan sekedar mengikuti kata hati tetapi cerdas menjalankan kepemimpinan sesuai dengan tuntutan jaman.Dia bukan sekadar baik hati tapi kompeten dan cemerlang menjalankan manajemen sekolah. Item yang mengukur visidalam alat ukur kepemimpinan pembelajaran yang digunakan dalam penelitian ini belum mengukur visisebagaimana dinyatakan oleh Pratikno (2011), yaitu visi yang berfokus pada anggota-anggota organisasi.

Analisis reliabilitas alat ukur yang dirancang dalam kepemimpinan pembelajaran dianalisis dengan analisis reliabilitas danmenghasilkan koefisien reliabilitas Alpha Cronbach sebesar 0,96 yang menunjukan adanya tingkat homogenitas item-item dalam alat ukur tersebut. Koefisien reliabilitas yang tinggi ini mengindikasikan adanya unidimensionalitas suatu alat ukur.Unidimensionalitas konstruksi kepemimpinan

pembelajaraniniditunjukkan juga oleh hasil analisis faktor. Muatan faktor mengumpul di satu faktor dengan besaran berkisar antara 0,46-0,76.

Kepemimpinan pembelajaran dapat meningkatkan kualitas prestasi belajar dan membetuk karakter atau watak siswa yang utuh. Hal ini sesuai denan tujuan utama kepemimpinan pembelajaran adalah memberikan layanan prima kepada semua siswa agar mereka mampu mengembangkan kualitas dasar dan instrumentalnya dalam menghadapi masa depan yang penuh gejolak sosial ketidakpastian dan tantangan yang sangat turbulen. Kepemimpinan pembelajaran harus diterapkan di sekolah dalam rangka menumbuhkan karakter siswa sesuai dengan nilainilai Pancasila. 


\section{SIMPULAN}

Kepemimpinan pembelajaran tepat diterapkan di sekolah untuk menumbuhkan karakter agar lebih efektif. Seluruh aspek kepemimpinan pembelajaran penting untuk diimplementasikan.Perilaku disiplin diriadalah aspek terpenting kepemimpinan pembelajaran, menyusul transparansi, moral/etika, dan interaksi edukatif. Aspek visi dan kesadaran diri dinilai paling rendah tingkat pentingnya, walaupun perilaku dalam aspek ini relatif masih dinilai penting oleh sebagian besar partisipan penelitian.

Penelitian ini membuktikan bahwa konstruksi kepemimpinan pembelajaran adalah unidimensionalitas. Artinya, konstruksi ini merupakan satu kontruksi yang utuh. Urutan tingkat penting dimensi kepemimpinan

pembelajarandiimplementasikan di sekolah untuk menanamkan karakter siswa, yaitu perilaku disiplin diri, transparansi, nilai/etika/moral, interaksi edukatif, visi, dan kaesadaran diri.

Kepemimpinan pembelajaran disarankan untuk diterapkan di sekolah. Hal ini karena, ia berkontribusi sangat signifikan terhadap peningkatan prestasi belajar dan menumbuhkan karakter siswa yang sesuai dengan nilai-nilai Pancasila. Di samping itu, ia juga mampu memfokuskan kegiatan semua warga sekolah untuk mencapai visi sekolah. Karena itu, kepemimpinan pembelajaran penting diterapkan di sekolah dalam rangka membangun komunitas atau sekolah belajar yang berkarakter.

\section{DAFTAR RUJUKAN}

Agung, I. 1992. Pengelolaan Sekolah dan Upaya Peningkatan Mutu
Pendidikan. Suara Guru (3): 1012.

Avolio, B., \& Gardner, W. 2005. Authentic leadership development: Getting to the root of positive forms of leadership. Leadership Quarterly, 16(3): 315-338.

Fink, E. \& Lauren, B.R. 2003. Developing Principals as Instructional Leaders. California: Sage Publication.

George, B. 2003 .Authentic Leadership: Rediscovering the Secrets to CreatingLasting Value.San Fransisco: JosseyBass.

Idris, J. 2005. Analisis Kritis Mutu Pendidikan. Yogyakarta: Suluh Press.

Kernis, M. H.2003. Toward a conceptualization of optimal selfesteem.Psychological Inquiry, 14: 1-26.

Pratikto, H. 2011. Strategi Implementasi Kewirausahaan Pusat Sumber BelajarBersama dalam Meningkatkan Kompetensi Tenaga Kependidikan.Jurnal IImuPendidikan, 17(6): 450.

Mulyasa, E. 2011. Manajemen Pendidikan Karakter. Jakarta: Bumi Aksara.

Ryan, W. 2008.Leadership with a Moral Purpose; Turning Your School InsideOut.UK: Crown House Publishing Ltd

Supardi, K. 2011. Kesehatan Sekolah, sumber Daya Manusia, PrestasiAkademik, dan Keefektifan SMP Standar Nasional. Jurnal IImu Pendidikan, 17(95): 387-392.

Zuchdi, D. 2012. Pendidikanj Karakter: Konsep Dasar dan Implementasi di Perguruan Tinggi. Yogyakarta: UNY Press. 